\title{
Chromosomal Instability in Farmers Exposed to Pesticides: High Prevalence of Clonal and Non-Clonal Chromosomal Alterations
}

This article was published in the following Dove Press journal: Risk Management and Healthcare Policy

\author{
Sebastian Cepeda' \\ Maribel Forero-Castro' \\ Diana Cárdenas-Nieto' \\ María Martínez-Agüero ${ }^{2}$ \\ Milena Rondón-Lagos' \\ 'School of Biological Sciences, \\ Universidad Pedagógica y Tecnológica de \\ Colombia, Tunja 150003, Colombia; \\ ${ }^{2}$ Biology Program, Faculty of Natural \\ Sciences and Mathematics, Universidad \\ del Rosario, Bogotá III22I, Colombia
}

Correspondence: Milena Rondón-Lagos School of Biological Sciences, Universidad Pedagógica y Tecnológica de Colombia, Tunja 150003, Colombia

Tel/Fax +57-8-7405626

Email sandra.rondon0I@uptc.edu.co

María Martínez-Agüero

Biology Program, Faculty of Natural Sciences and Mathematics, Universidad del Rosario, Bogotá III22I, Colombia $\mathrm{Tel} / \mathrm{Fax}+57-\mathrm{I}-297-0200$ ext. 4029

Email maria.martinez@urosario.edu.co
Introduction: An important economic activity in Colombia is agricultural production and farmers are frequently exposed to pesticides. Occupational exposure to pesticides is associated with an increased incidence of various diseases, including cancer, Parkinson's disease, Alzheimer's disease, reproductive disorders, and birth defects. However, although high genotoxicity is associated with these chemicals, information about the type and frequency of specific chromosomal alterations (CAs) and the level of chromosomal instability (CIN) induced by exposure to pesticides is scarce or absent.

Methods: In this study, CAs and CIN were assessed in peripheral blood lymphocytes (PBLs) from five farmers occupationally exposed to pesticides and from five unexposed individuals using GTG-banding and molecular cytogenetic analysis.

Results: A significant increase in clonal and non-clonal chromosomal alterations was observed in pesticide-exposed individuals compared with unexposed individuals $(510 \pm 12,2$ vs $73 \pm 5,7$, respectively; $p<0.008$ ). Among all CAs, monosomies and deletions were more frequently observed in the exposed group. Also, a high frequency of fragilities was observed in the exposed group.

Conclusion: Together, these findings suggest that exposure to pesticides could be associated with CIN in PBLs and indicate the need for the establishment of educational programs on safety precautions when handling pesticides, such as wearing gloves, masks and boots, changing clothes and maintaining proper hygiene, among others. Further evaluation in other similar studies that include a greater number of individuals exposed to pesticides is necessary.

Keywords: pesticides, occupational exposure, chromosomal instability, clonal chromosomal alteration, non-clonal chromosomal alteration

\section{Introduction}

In Colombia, one of the most important economic activities is agricultural production and farmers are frequently exposed to pesticides. Pesticides play an important role in the control of agricultural pests, and include several categories of fungicides, insecticides, herbicides, and others, with organophosphorus pesticides being the most frequently used. ${ }^{1}$

Exposure to pesticides is concerning because many studies have associated occupational exposure to these chemicals with an increased incidence of various diseases, including cancer, Parkinson's disease, Alzheimer's disease, reproductive disorders, and birth defects. $^{2}$ Exposure to pesticides can induce oxidative stress by increased production of free radicals, which accumulate in cells and can cause gene mutations and chromosomal aberrations. $^{3-5}$ 
In recent years, genotoxicity from exposure to pesticides has been extensively investigated in cell lines and animal models. However, although many cases of pesticide poisoning throughout the world are documented every year, data concerning chromosomal damage in occupationally exposed people is limited. ${ }^{6}$ Chromosomal alterations (CAs) related to pesticide exposure have been identified in several populations, and while some significant differences in the frequency of CAs in exposed individuals compared to unexposed controls have been reported, ${ }^{7-12}$ other studies have not observed any association. ${ }^{13,14}$ Furthermore, although some studies have shown the induction of CAs in humans, they have mainly reported alterations such as associations of satellites (between acrocentric chromosomes), gaps, ${ }^{15}$ ruptures, sisterchromatid exchanges, ${ }^{16}$ and micronuclei, so the level of chromosomal instability (CIN) induced by exposure to pesticides is poorly documented. Furthermore, information about the type and frequency of specific CAs induced by exposure to pesticides is scarce or absent.

The assessment of chromosomal damage in occupationally exposed humans is useful for measuring the genetic risk in the exposed population, ${ }^{17,18}$ and also an important step in the early detection of diseases when control measures could prove effective. CAs in peripheral blood lymphocytes (PBLs) reflect sensitivity to both exogenous and endogenous genotoxic substances and could be used as biomarkers of chromosomal damage and possible risk of developing diseases, including cancer. Further, these analyses are considered reliable and are an important tool to estimate both biological and genetic risk factors, related to pesticide exposure. ${ }^{19-21}$ The aim of this study was to evaluate $\mathrm{CIN}$ in farmers occupationally exposed to pesticides in the department of Cundinamarca, Colombia.

\section{Materials and Methods}

\section{Study Population}

The study was carried out on a group of five individuals from the department of Cundinamarca, Colombia who were routinely "exposed" to pesticides. The exposed individuals consisted of men and women between 51 and 66years-old and who had been exposed to pesticides through work for at least 12 months.

The unexposed group consisted of five healthy men and women, without indication of previous occupational exposure to pesticides. The group had a similar age range (between 52 and 63 years old), sex distribution and lifestyle habits as the exposed group (Tables 1 and 2).
Each individual was personally interviewed and filled in a routine questionnaire to record possible confounding factors such as diseases, age, smoking and drinking habits, exposure to pesticides, duration of exposure to pesticides and the use of protection devices (Table 1). Individuals

Table I General Characteristics of the Groups Studied

\begin{tabular}{|c|c|c|}
\hline & Exposed & Unexposed \\
\hline Number & 5 & 5 \\
\hline Age (mean \pm SD) & $57 \pm 6.2$ & $56.4 \pm 5.5$ \\
\hline \multicolumn{3}{|l|}{ Gender (n) } \\
\hline Male & 3 & 3 \\
\hline Female & 2 & 2 \\
\hline Exposure months (mean \pm SD) & $154.8 \pm 152.2$ & 0 \\
\hline \multicolumn{3}{|l|}{ Smoking status (n) } \\
\hline Smokers & I & 1 \\
\hline Non-smokers & 4 & 4 \\
\hline \multicolumn{3}{|l|}{ Drinking status (n) } \\
\hline Drinkers & 3 & 4 \\
\hline Non-drinkers & 2 & I \\
\hline
\end{tabular}

Abbreviation: SD, Standard Deviation.

Table 2 Detailed Characteristics and Percentages of Chromosome Variants (CVs) and Chromosomal Alterations (CAs) Identified in the Exposed and Unexposed Groups

\begin{tabular}{|c|c|c|c|c|c|}
\hline & \multirow{2}{*}{$\begin{array}{l}\text { Age } \\
\text { (Years) }\end{array}$} & \multirow{2}{*}{$\begin{array}{l}\text { Exposure } \\
\text { (Months) }\end{array}$} & \multicolumn{2}{|l|}{ Habits } & \multirow{2}{*}{$\begin{array}{l}\% \text { of } \\
\text { CVs } \\
\text { and } \\
\text { CAs }\end{array}$} \\
\hline & & & Smoking & Drinking & \\
\hline Exposed & & & & & \\
\hline $\mathrm{EI}$ & 66 & 120 & - & - & 41 \\
\hline E2 & 63 & 60 & - & I/week & 26 \\
\hline E3 & 52 & 48 & - & - & 32 \\
\hline E4 & 51 & 126 & - & I/month & 32 \\
\hline E5 & 53 & 420 & + & $1 /$ month & 19 \\
\hline Mean & 57 & 154.8 & & & \\
\hline Median & 53 & 120 & & & \\
\hline Unexposed & & & & & \\
\hline $\mathrm{Cl}$ & 63 & - & - & I/month & 9 \\
\hline $\mathrm{C} 2$ & 62 & - & - & $1 /$ month & 4 \\
\hline $\mathrm{C} 3$ & 52 & - & - & - & 10 \\
\hline $\mathrm{C} 4$ & 52 & - & - & $\begin{array}{l}\text { I/six } \\
\text { months }\end{array}$ & 4 \\
\hline $\mathrm{C} 5$ & 53 & - & - & I/week & 8 \\
\hline Mean & 56.4 & & & & \\
\hline Median & 54.7 & & & & \\
\hline
\end{tabular}


who had suffered from cancer or had received radiotherapy, chemotherapy, or other recent prolonged medical treatment were excluded.

Data from the five exposed individuals were compared with those of the unexposed individuals. This study was approved by Ethics Committee of Universidad Pedagógica y Tecnológica de Colombia, Tunja (Colombia) and was conducted in accordance with the Declaration of Helsinki. Before blood sampling, a written informed consent was obtained from each participating subject.

\section{Blood Sampling}

Peripheral blood samples from exposed and unexposed individuals were collected in blood collection tubes containing heparin by venous puncture. The samples were labeled, transported to the laboratory, and immediately processed.

\section{Metaphase Spreads and G-Banding Using Trypsin and Giemsa Stain}

Metaphases were obtained using standard harvesting protocols for banding and molecular cytogenetic analysis. Briefly, $1 \mathrm{~mL}$ of heparinized peripheral blood were cultured in duplicates in 5 mL RPMI-1640 medium (Sigma, St. Louis, MO, USA), supplemented with $100 \mu \mathrm{L}$ phytohemaglutinin-M (Gibco, Life Technologies, Nebraska, USA) and 10\% fetal bovine serum (FBS) (Sigma). The cultures were incubated for $72 \mathrm{~h}$ at $37^{\circ} \mathrm{C}$ in $5 \% \mathrm{CO}_{2}$ atmosphere. After $72 \mathrm{~h}$, N-Deacetyl-N-methylcolchicine solution $(0.0001 \mathrm{~g} / \mathrm{mL}$ final conc.) (Sigma) was added to cultures $25 \mathrm{~min}$ before cell harvesting. Then, cells were treated with $\mathrm{KCl}$ solution at a concentration of $0.075 \mathrm{M}$ (hypotonic solution), fixed with Carnoy's fixative (3:1 methanol to acetic acid) three times and spread on glass slides. Thus obtained, the chromosomal preparations were banded with GTG-Banding using trypsin solution (0.25\%) (Gibco) and Giemsa stain (Sigma).

\section{GTG-Banding Cytogenetic Analysis}

Characterization of CIN by using G-Banding cytogenetic was performed on a total of 544 metaphases. Image acquisition and karyotyping of metaphases were performed using an Olympus microscope with cytogenetic software, Cytovision System 7.4 (Leica Biosystems Richmond, VA, USA). Fragilities (fra), variation in length of heterochromatic segments on the long arms of chromosomes 1 (1qh $+), 9(9 \mathrm{qh}+)$ and $16(16 \mathrm{qh}+)$; inversion of chromosome 9 [inv(9)]; chromosomal breaks (chrb) and chromatid breaks (chrb), and CAs including structural (SCAs) and numerical chromosomal alterations (NCAs) were evaluated. All chromosome variations and CAs were described according to the International System for Human Cytogenomic Nomenclature (ISCN) $2016 .^{22}$

\section{Fluorescence in situ Hybridization (FISH) and $\mathrm{CIN}$ Evaluation}

CIN was evaluated on the metaphase and nuclei spreads obtained previously by FISH using six centromeric probes (CEP) for chromosomes 2, 3, 8, 11, 15 and 17 (all from Cytocell, Cambridge) and standard procedures. Briefly, slides were dehydrated in ethanol series before hybridization with FISH probes. Three-color FISH was performed on nuclei/metaphase spreads for chromosomes 2, 8 and 11, and for chromosomes 3,15 and 17, using centromeric probes labeled with different spectrum colors: spectrum orange for CEP2 and CEP3; spectrum green for CEP8 and CEP17; and spectrum aqua for CEP11 and CEP15. After the addition of the probe mix, the slides were codenatured in the Top Brite System (Resnova, Italy) at $75^{\circ} \mathrm{C}$ for 2 mins and hybridized overnight at $37^{\circ} \mathrm{C}$. Slides were then washed, dehydrated, and counterstained with 4',6-diamidino-2-phenylindole (Cytocell). Ten randomly selected areas of each exposed and unexposed individual were acquired using an Olympus microscope with the cytogenetic software Cytovision System 7.4 (Leica Biosystems Richmond, Inc.). CIN was assessed in a minimum of 100 intact and non-overlapping nuclei/metaphases for each chromosome.

Although some studies have shown that the use of probes for only two chromosomes is enough to differentiate diploid from aneuploid tumors, ${ }^{23}$ we decided to use six probes since the use of more than two probes allows the identification of clonal populations with greater certainty. ${ }^{24}$

\section{Data Analysis}

Fisher's exact test, Student's $t$-test and Wilcoxon test were performed to compare the GTG-banding cytogenetic data with parametric and non-parametric distribution, respectively. Normality of the data was evaluated by the ShapiroWilk test. Data from the exposed individuals were compared with those of the unexposed individuals. $p$ values less than 0.05 were considered significant $(* p \leq 0.05 * * p \leq 0.01)$. All statistical analyses were performed using IBM-SPSS Statistics Developer (Version 21.0 IBM Company, Chicago, IL). The CIN rate for each exposed and unexposed individual was defined first by calculating the percentage of nuclei with 
a CEP signal number different to the modal number (most common chromosome number in a tumor cell population) for each individual chromosome and then calculating the mean CIN percentage of all chromosomes analyzed. ${ }^{25,26}$ According to the level of CIN, each exposed and unexposed individual was classified as having low $\mathrm{CIN}(\mathrm{CIN}<25 \%)$ or high $\mathrm{CIN}(\mathrm{CIN} \geq 25 \%)^{27,28}$

\section{Results}

\section{Characteristics of Study Groups}

GTG-Banding and molecular cytogenetics were used in order to evaluate chromosomal alterations and CIN in a group of farmers exposed to pesticides and in a control group. General and detailed characteristics of the groups studied (exposed and unexposed) are presented in Tables 1 and 2 , respectively. For the exposed group, the median time of exposure to pesticides was 120 months and the median age was 53 years (Table 2). In both groups, exposed and unexposed, a low prevalence of smoking and alcoholic beverage consumption was reported. The results are expressed as the mean \pm standard deviation (SD) (Tables 1 and 2). Pesticides to which farmers were mainly exposed included fungicides, insecticides and herbicides (Table 3).

\section{GTG-Banding Cytogenetic Results}

To define fragilities (fra), chromosome variants (CVs) (increase in length of heterochromatic segments of chromosomes 1, 9 and 16), chromosome breaks (chrb), chromatid breaks (chtb), and clonal (CCA) and non-clonal (NCCA) chromosomal alterations (numerical and structural chromosomal alterations), between 20 and 95 metaphases

Table 3 Pesticides Most Commonly Used by Exposed Individuals

\begin{tabular}{|l|l|l|}
\hline Pesticide & Active Ingredient & Commercial Name \\
\hline Fungicide & $\begin{array}{l}\text { Mancozeb }+ \\
\text { Cymoxanil } \\
\text { Mancozeb } \\
\text { Cymozeb } \\
\text { Propineb } \\
\text { Propineb; Cymoxanil }\end{array}$ & $\begin{array}{l}\text { Curathane; Curzate M-8; } \\
\text { Cymozeb } \\
\text { Insecticide }\end{array}$ \\
& $\begin{array}{l}\text { Imidacloprid } \\
\text { Cymoxanil and Mancozeb } \\
\text { Profenofos } \\
\text { Lambda-cyhalothrin } \\
\text { Carbosulfan } \\
\text { Carbofuran } \\
\text { Chlorpyrifos }\end{array}$ & $\begin{array}{l}\text { Confidor } \\
\text { Curacron } \\
\text { Eltra 48 }\end{array}$ \\
\hline Herbicide & Furadan \\
Laraquat & Gramon \\
\hline
\end{tabular}

with good chromosome morphology and chromosome dispersion, were analyzed from individuals of both groups (exposed and unexposed). In total 544 metaphases were analyzed. GTGbanding cytogenetic analysis for both, exposed and unexposed groups, demonstrated a modal diploid number $(2 n)$. As shown in the Figures 1 and 2, significantly high frequencies for fragilities, variation in length of heterochromatic segments on the long arms of chromosomes $1(1 \mathrm{qh}+), 9(9 \mathrm{qh}+)$ and 16 $(16 \mathrm{qh}+)$; inversion of chromosome 9 [inv(9)]; chromosomal breaks (chrb) and chromatid breaks (chrb), and CAs including structural (SCAs) and numerical chromosomal alterations (NCAs), were found in the exposed group compared with those observed in the unexposed group (510 and 73, respectively) ( $p \leq 0.008$; Wilcoxon test) (Table 4 ).

In addition, we assessed the effect of smoking and alcohol consumption as confounding factors on the frequency of CVs, chromosome breaks (chrb), chromatid breaks (chtb), and clonal (CCA) and non-clonal (NCCA) chromosomal alterations (numerical and structural chromosomal alterations) in all study subjects. Our results indicate that neither alcohol consumption nor cigarette smoking increase the frequency of CVs and CAs in any of the groups studied, exposed and unexposed (Table 2).

\section{Fragilities}

A high frequency of fra was found in the exposed group (212 fragilities) (Figure 1A) compared with the unexposed group (39 fragilities) (Figure 1B). In the exposed and unexposed groups, fra(9)(q12) was the most frequent (115/212 and 33/ 39 , respectively) (Table 4, Figure $3 \mathrm{~A}$ ) and was present in $100 \%$ of the exposed and unexposed individuals (Table S1). Comparison of the presence of fra between exposed and unexposed groups showed a significant difference $(p \leq 0.005)$ (Table 4$)$. In both exposed and unexposed groups many of the fragilities were non-clonal (Table S1).

\section{Variation in Length of Heterochromatic Segments}

High frequency of increase in the length of heterochromatic segments on the long arms of chromosomes 1 (1qh+) and 16 $(16 \mathrm{qh}+)$ was identified in $100 \%$ and $60 \%$ of the exposed individuals, respectively, and in none of the unexposed individuals (Table 4 and Figures 1 and 2). Comparison of the presence of $1 \mathrm{qh}+$ and $16 \mathrm{qh}+$ between exposed and unexposed groups showed significant differences $(p \leq 0.001$, Fisher's exact test) (Tables 4 and $\underline{\mathrm{S} 2}$ ).

Chromatid and Chromosomic Breakage (Chtb/Chrb) Also, higher frequencies of chrb and chtb were observed in the exposed group (59 breaks) compared with those observed 
A

\begin{tabular}{|c|c|c|c|c|c|c|c|c|c|c|c|c|c|c|}
\hline Exposed & fra & $1 q h+$ & $9 q h+$ & $\begin{array}{l}\text { fra(9) } \\
\text { (q12) }\end{array}$ & $\operatorname{inv}(9)$ & $16 q h+$ & $\begin{array}{l}\text { chtb/ } \\
\text { chrb }\end{array}$ & M & $\mathbf{T}$ & del & der & $\mathbf{t}$ & other & Total \\
\hline \multicolumn{15}{|l|}{1} \\
\hline \multicolumn{15}{|l|}{2} \\
\hline \multicolumn{15}{|l|}{3} \\
\hline \multicolumn{15}{|l|}{4} \\
\hline \multicolumn{15}{|l|}{5} \\
\hline Total & & & & & & & & & & & & & & \\
\hline
\end{tabular}

B

\begin{tabular}{|c|c|c|c|c|c|c|c|c|c|c|c|c|c|c|}
\hline Unexposed & fra & $1 \mathrm{qh}+$ & $9 q h+$ & $\begin{array}{l}\text { fra(9) } \\
\text { (q12) }\end{array}$ & $\operatorname{inv}(9)$ & $16 q h+$ & $\begin{array}{l}\text { chtb/ } \\
\text { chrb }\end{array}$ & M & $\mathbf{T}$ & del & der & $\mathbf{t}$ & other & Total \\
\hline \multicolumn{15}{|l|}{1} \\
\hline \multicolumn{15}{|l|}{2} \\
\hline \multicolumn{15}{|l|}{3} \\
\hline \multicolumn{15}{|l|}{4} \\
\hline \multicolumn{15}{|l|}{5} \\
\hline Total & & & & & & & & & & & & & & \\
\hline
\end{tabular}

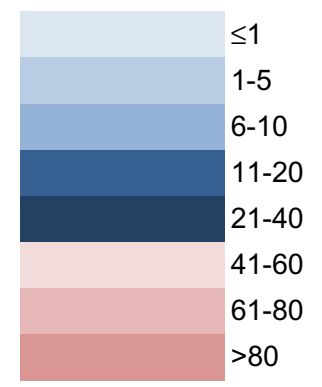

Figure I Frequency of chromosome variants (CVs) and chromosomal alterations (CAs) in peripheral blood lymphocytes (PBLs) from farmers exposed to pesticides (A) and from unexposed individuals (B). The frequency of each CV and CA is indicated for each exposed and unexposed individual using a color code for each category according to the legend at the bottom.

Abbreviations: fra, fragilities; I qh+, increase in length of the heterochromatic segment on the long arm of chromosome I; 9qh+, increase in length of the heterochromatic segment on the long arm of chromosome 9; fra(9)(q/2), fragility in the long arm of chromosome 9, region I and band 2; inv(9), inversion of chromosome 9; I6qh+, increase in length of the heterochromatic segment on the long arm of chromosome 16; chtb/chrb, chromatidic/chromosomic break; M, monosomies; T, trisomies; del, chromosomal deletions; der, derivative chromosomes; t, chromosomal translocations; other, other structural chromosomal alterations.

in the unexposed group ( 9 breaks) (Table 4). In the exposed group the chromosomes most affected by such changes were chromosomes 9, 1, 5 and 6 (Table S3). The frequency of chrb and chtb between exposed and unexposed groups showed statistically significant differences $(p \leq 0.004)$ (Table 4$)$.

\section{Numerical (NCAs) and Structural Chromosomal Alterations (SCAs)}

In the exposed and unexposed groups, 119 NCAs and 24 SCAs were observed, respectively (Table 4). In the exposed group, NCAs (93/119) were more frequent than SCAs (26/119) (Figures 1 and 2). Similar results were observed in the unexposed group, where NCAs (23/24) were also more frequent than SCAs (1/24). When exposed and unexposed groups were compared, the frequency of
NCAs and SCAs showed significant differences $(p \leq 0.006$ and $p \leq 0.03$, respectively) (Table 4 ).

\section{Numerical Chromosomal Alterations}

The NCAs identified in both groups were mainly monosomies, while trisomies were less frequently observed and were non-clonal (NCCAs). Note that in the exposed group, monosomy of the $\mathrm{X}$ chromosome (Figure $3 \mathrm{~B}$ ) was most frequently found in exposed females, but not exposed males, followed by monosomies of chromosomes 10 and 20, which showed statistically significant differences compared with the monosomies observed in the unexposed group $(p \leq 0.006)$ (Tables 4

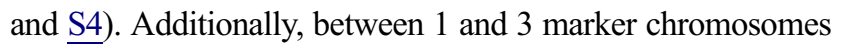
(mar) were identified in all exposed individuals, which were absent in the unexposed group (Table S4). 


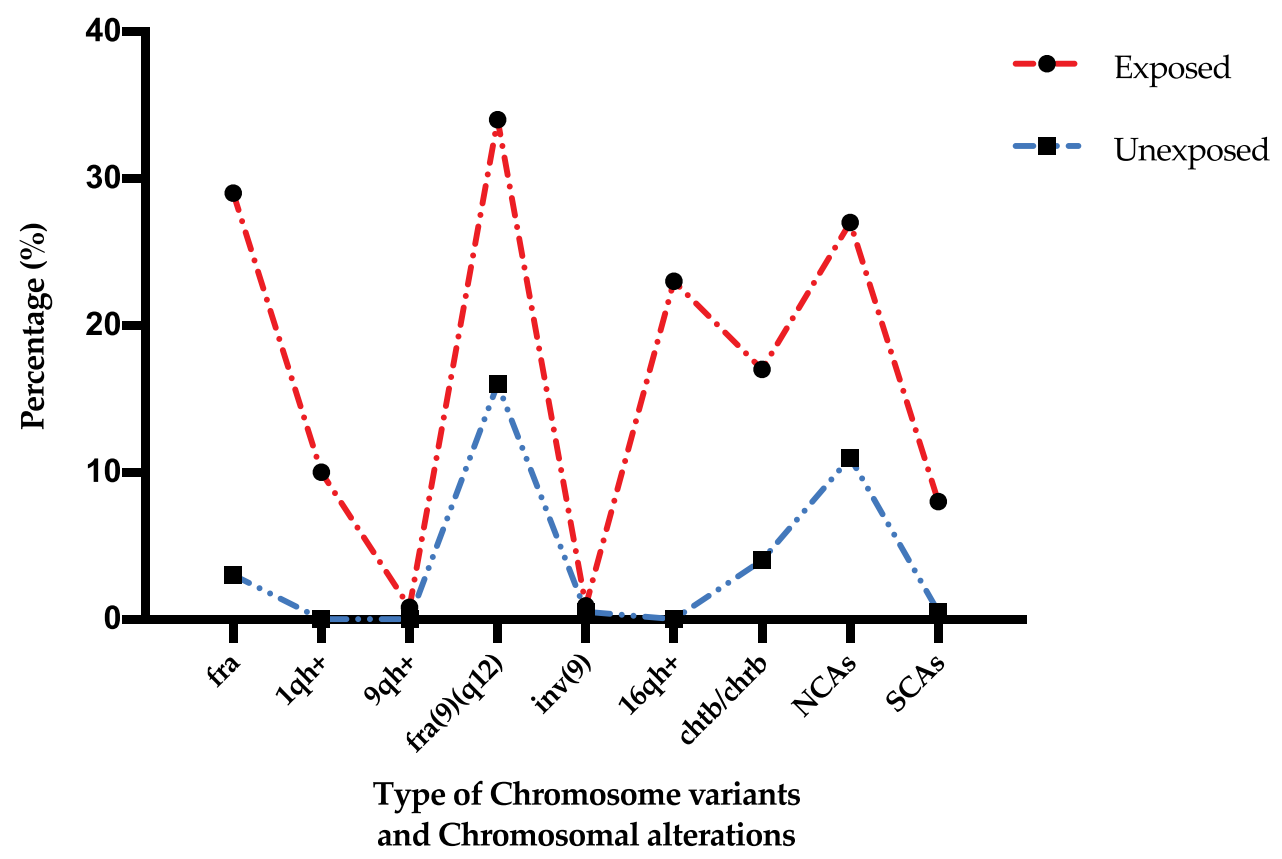

Figure 2 Percentages of chromosome variants and chromosomal alterations observed in the exposed and unexposed groups.

Abbreviations: fra, fragilities; I qh+, increase in length of the heterochromatic segment on the long arm of chromosome I; 9qh+, increase in length of the heterochromatic segment on the long arm of chromosome 9; inv(9), inversion of chromosome 9; I6qh+, increase in length of the heterochromatic segment on the long arm of chromosome 16; chtb/chrb, chromatidic/chromosomic break; NCAs, numerical chromosomal alterations; SCAs, structural chromosomal alterations.

\section{Structural Chromosomal Alterations}

A higher frequency of non-clonal SCAs was identified in the exposed group (26/119) compared with those observed in the unexposed group (1/24). SCAs were observed in all individuals of the exposed group (100\%), including dicentric chromosomes (dic), deletions (del), translocations ( $\mathrm{t}$ ), inversions (inv), derivative chromosomes (der) and ring chromosomes (r), while in the unexposed group only one

Table 4 Frequencies and Percentages of Chromosome Variants (CVs) and Chromosomal Alterations (CAs) Identified in the Exposed and Unexposed Groups

\begin{tabular}{|c|c|c|c|c|c|}
\hline \multirow[t]{2}{*}{ CVs and CAs } & \multicolumn{2}{|c|}{ Number of Individuals } & \multicolumn{3}{|c|}{ Number of Alterations } \\
\hline & Exposed n (\%) & Unexposed n (\%) & Exposed n (\%) & Unexposed n (\%) & $p^{+}$ \\
\hline fra & $5(100)$ & $5(100)$ & $97(28)$ & $6(3)$ & $0.0000 I^{* *}$ \\
\hline Iqh+ & $5(100)$ & $0(0)$ & $35(10)$ & $0(0)$ & $0.0015^{* *}$ \\
\hline $9 q h+$ & I (20) & $0(0)$ & $3(0.9)$ & $0(0)$ & I \\
\hline $\operatorname{fra}(9)(q \mid 2)$ & $5(100)$ & $5(100)$ & $115(34)$ & $33(16)$ & $0.0052 * *$ \\
\hline $\operatorname{inv}(9)$ & $2(40)$ & I (20) & $3(0.9)$ & $\mathrm{I}(0.5)$ & 0.6212 \\
\hline $16 q h+$ & $3(60)$ & $0(0)$ & $79(23)$ & $0(0)$ & $0.000001 * *$ \\
\hline chtb/chrb & $5(100)$ & $4(80)$ & $59(17)$ & $9(4)$ & $0.0046 * *$ \\
\hline NCAs & $5(100)$ & $5(100)$ & $93(27)$ & $23(\mathrm{II})$ & $0.0063 * *$ \\
\hline SCAs & $5(100)$ & I (20) & $26(8)$ & I $(0.5)$ & $0.0349 *$ \\
\hline Total & & & 510 & 73 & \\
\hline Mean & & & 16.5 & 3.9 & \\
\hline SD & & & 12.2 & 5.7 & \\
\hline$p^{++}$ & & & $0.008^{* *}$ & & \\
\hline
\end{tabular}

Notes: $*$ Statistically significant difference relative to the unexposed group at $p \leq 0.05$. **Statistically significant difference relative to the unexposed group at $p \leq 0.01$ ( ${ }^{+}$: Fisher's exact test; $\mathrm{P}^{++}$: Wilcoxon test).

Abbreviation: SD, standard deviation. 


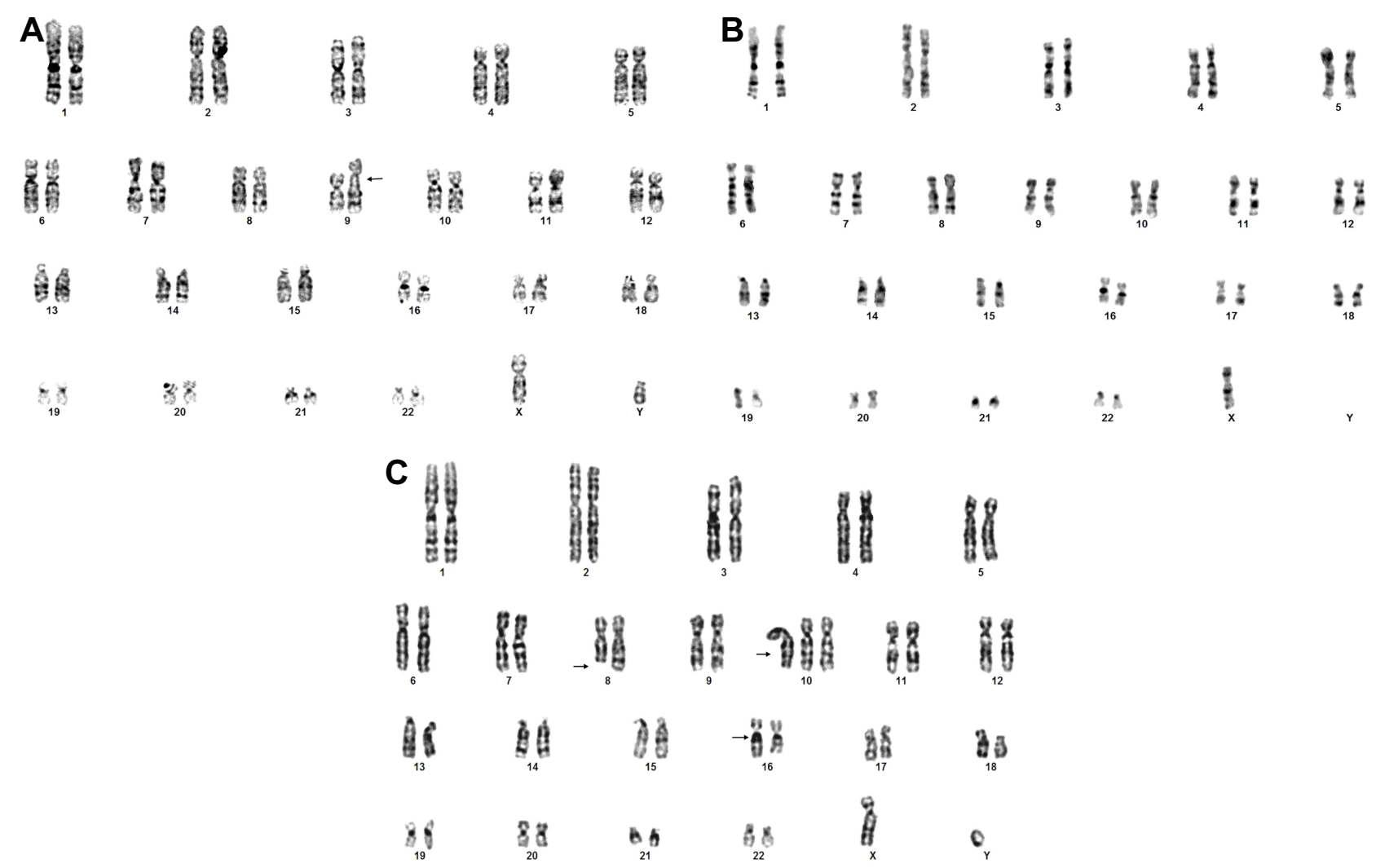

Figure 3 Representative karyotypes of exposed individual showing: (A) Fragility of the long arm of chromosome 9: 46,XY,fra(9)(q।2). (B) Monosomy of chromosome X:45, $\mathrm{X},-\mathrm{X}$. (C) Numerical and structural chromosomal alterations: 47,XY,del(8)(q23),+10,16qh+. Arrows indicate chromosomal alterations.

deletion in one individual was observed (Table 6). Among all SCAs, deletions were most frequently found (10/26) in all exposed individuals, followed by translocations $(6 / 26)$ and derivative chromosomes (5/26) (Figure 1 and Table 5). Note that the chromosome most affected by SCAs in the exposed group was chromosome 8, where deletions and translocations were prevalent (Table 5 and Figure 3C).

Comparison of the presence of fragilities, variation in length of heterochromatic segments on the long arms of chromosomes 1, 9 and 16, chromosomal and chromatid breaks, and CAs between paired exposed/unexposed individuals showed statistically significant differences (Table 6).

\section{Molecular Cytogenetic (Fluorescence in situ Hybridization) Results}

In order to better quantify the level of CIN in exposed compared to unexposed individuals, we assessed CIN by using centromeric FISH in 100 interphase nuclei and some metaphases. The CIN rate for each exposed and unexposed individual was defined first by calculating, for each of the six chromosomes separately, the percentage of nuclei with a CEP signal number different to the modal number, and then calculating the mean CIN percentage of all six chromosomes analyzed (Table S5).

Exposed individuals showed a high CIN ( $\geq 25 \%$ ) compared with a low CIN ( $\leq 14 \%)$ observed in unexposed individuals (Figures 4 and 5, and Table S5). More specifically, in exposed individuals, CIN ranged between $41 \%$ and $45 \%$, while in non-exposed individuals, CIN ranged between 4\% and 14\% (Figures 4 and 5). These results suggest that pesticides can induce aneuploidy, which is indicative of numerical CIN.

\section{Discussion}

In Colombia, one of the most important economic activities is agricultural production, which results in farmers being exposed to pesticides. Many of these pesticides are carcinogenic and mutagenic. It is well known that chromosomal alterations are causal events in the development of neoplasms. ${ }^{29}$ Therefore, cytogenetic damage may reflect an increase in cancer risk. ${ }^{21,30}$ However, although many studies have reported high genotoxicity associated with these chemicals, in Colombia, information about the type and frequency of specific CAs and the level of CIN 
Table 5 Type and Frequency of Structural Chromosomal Alterations (SCAs) Observed in Exposed (E) and Unexposed (C) Groups. The Frequency of Each SCAs Is Indicated for Each Exposed and Unexposed Individual Using a Color Code for Each Category According to the Legend to the Right

\begin{tabular}{|c|c|c|c|c|c|c|c|c|c|c|c|}
\hline SCA & E1 & E2 & E3 & E4 & E5 & C1 & $\mathrm{C} 2$ & C3 & C4 & C5 & \\
\hline \multicolumn{12}{|l|}{$? \operatorname{dic}(X ; ? 17)(q 22 ; ? p 13)$} \\
\hline \multicolumn{12}{|l|}{$? \operatorname{del}(\mathrm{X})(\mathrm{p} 11.2)$} \\
\hline \multicolumn{12}{|l|}{$r(Y)(p 11.3 ; q 12)$} \\
\hline \multicolumn{12}{|l|}{$\mathrm{t}(1 ; 6)(\mathrm{q} 32 ; q 27)$} \\
\hline \multicolumn{12}{|l|}{$\operatorname{inv}(2)(p 22 ; q 12)$} \\
\hline \multicolumn{12}{|l|}{$\mathrm{t}(3 ; 10)(p 14 ; q 24)$} \\
\hline \multicolumn{12}{|l|}{$\mathrm{t}(4 ; 6)(\mathrm{q} 35 ; \mathrm{q} 31)$} \\
\hline \multicolumn{12}{|l|}{$\operatorname{der}(5) \operatorname{add}(5)(p 15)$} \\
\hline \multicolumn{12}{|l|}{$\operatorname{del}(6)(q 27)$} \\
\hline \multicolumn{12}{|l|}{$\operatorname{add}(7)(q 36)$} \\
\hline \multicolumn{12}{|l|}{$\operatorname{del}(7)(p 14)$} \\
\hline \multicolumn{12}{|l|}{$\operatorname{der}(8) t(1 ; 8)(q 25 ; q 13)$} \\
\hline \multicolumn{12}{|l|}{$\operatorname{der}(8) t(8 ; 15)(p 12 ; q 21)$} \\
\hline \multicolumn{12}{|l|}{$\operatorname{del}(8)(p 22)$} \\
\hline \multicolumn{12}{|l|}{$\operatorname{del}(8)(q 23)$} \\
\hline \multicolumn{12}{|l|}{$\operatorname{del}(9)(p 21)$} \\
\hline \multicolumn{12}{|l|}{$? \operatorname{del}(10)(q 11.2)$} \\
\hline \multicolumn{12}{|l|}{$\operatorname{add}(11)(p 15)$} \\
\hline \multicolumn{12}{|l|}{$\operatorname{del}(12)(q 24.1)$} \\
\hline \multicolumn{12}{|l|}{$\operatorname{der}(12) \operatorname{add}(12)(p 13)$} \\
\hline \multicolumn{12}{|l|}{$\mathrm{t}(18 ; 22)(\mathrm{p} 11.21 ; \mathrm{q} 12)$} \\
\hline \multicolumn{12}{|l|}{$\operatorname{der}(18) t(18 ; 19)(p 11 ; p 11)$} \\
\hline \multicolumn{12}{|l|}{$\operatorname{del}(19)(p 11)$} \\
\hline \multicolumn{12}{|l|}{$\operatorname{del}(19)(p 12)$} \\
\hline ?rob(22;22)(q11.1;q11.1) & & & & & & & & & & & \\
\hline
\end{tabular}

Abbreviations: dic, dicentric chromosome; del, chromosome deletion; $r$, ring chromome; t, chromosome translocation; inv, chromosome inversion; add, additional material of unknown origin; rob, Robertsonian translocation.

induced by exposure to pesticides is scarce or absent. Considering the above, the aim of our study was to evaluate CAs and CIN induced by pesticides in peripheral blood lymphocytes (PBLs) from farmers occupationally exposed to pesticides.

The results obtained using GTG-Banding and FISH analysis of a large number of metaphases, allowed us to identify previously unreported CVs and CAs in farmers exposed to pesticides. The mean number of CVs and CAs observed in the exposed individuals was seven times higher than that in the unexposed individuals. The above suggests a possible cytogenetic effect of pesticides on occupationally exposed farmers in the Department of Cundinamarca, Colombia. Numerical and structural CIN was also observed in both, exposed and unexposed groups, with a higher and statistically significant prevalence in the exposed group. However, it is important to highlight that many of the numerical and structural alterations observed were NCCAs.

In the exposed group, the monosomies were the CAs most frequently observed compared with those observed in 
Table 6 Frequency and Percentage of Chromosome Variants (CVs) and Chromosomal Alterations (CAs) Identified in Paired Exposed/Unexposed Individuals

\begin{tabular}{|l|l|l|l|l|l|}
\hline \multirow{2}{*}{ No } & \multicolumn{2}{|l|}{ Exposed } & \multicolumn{2}{l|}{ Unexposed } & \multirow{2}{*}{ P } \\
\cline { 2 - 5 } & $\mathbf{n}$ & $\%$ & $\mathbf{n}$ & $\%$ & \\
\hline 1 & 138 & 41 & 18 & 9 & $0.000 I^{* *}$ \\
2 & 89 & 26 & 9 & 4 & $0.000 I^{* *}$ \\
3 & 109 & 32 & 21 & 10 & $0.0002^{* *}$ \\
4 & 109 & 32 & 9 & 4 & $0.000 I^{* *}$ \\
5 & 65 & 19 & 16 & 8 & $0.037^{*}$ \\
\hline
\end{tabular}

Notes: *Statistically significant difference relative to the unexposed group at $p \leq 0.05$. **Statistically significant difference relative to the unexposed group at $p \leq 0.01$ (Fisher's exact test).

the unexposed group. Monosomies have been correlated with hematological malignancies in several recent studies. ${ }^{31}$ For instance, monosomy of chromosome $\mathrm{X}$, observed at high frequency in two exposed individuals, has been correlated with autoimmune disease in females, ${ }^{32,33}$ autoimmune thyroid disease and systemic sclerosis. ${ }^{34}$ Furthermore, a high frequency of monosomy $\mathrm{X}$ was found in peripheral leukocytes from patients with primary biliary cirrhosis. ${ }^{35}$ Interestingly, it has been proposed that xenobiotics, including pesticides, may be environmental triggers of primary biliary cirrhosis in genetically susceptible individuals. ${ }^{36-38}$ The above studies demonstrate a possible link between pesticide exposure, chromosome $\mathrm{X}$ monosomy and disease. In addition, chromosome 10 trisomy, observed in $40 \%$ of exposed

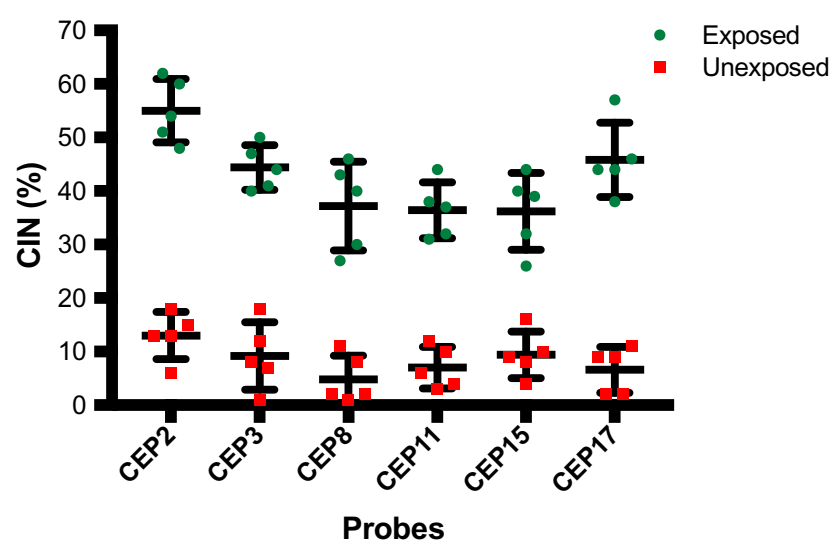

Figure 4 Percentage of Chromosomal Instability (CIN) observed in peripheral blood lymphocytes (PBLs) from farmers exposed to pesticides and from unexposed individuals. $\mathrm{CIN}$ was evaluated on nuclei spreads by using FISH with six centromeric probes (CEP) for chromosomes 2, 3, 8, II, 15 and 17. The CIN rate for each exposed and unexposed individual was defined first by calculating the percentage of nuclei with a CEP signal number different to the modal number (most common chromosome number in a tumor cell population) for each individual chromosome and then calculating the mean $\mathrm{CIN}$ percentage of all chromosomes analyzed. The bars indicate the mean and standard deviation of each probe in each group (exposed and unexposed). and in $0 \%$ of non-exposed subjects, has been reported as a non-random anomaly in myeloid disorders. ${ }^{39,40}$ Aneuploidy, defined as the loss or gain of complete chromosomes, is a characteristic of tumor cells associated with cellular stress. ${ }^{41}$

Regarding structural chromosomal alterations, this type of alterations may alter the relative dosage of genes on the affected chromosomes, which could lead to the development of diseases, including cancer. In fact, it has been reported that unbalanced chromosomal abnormalities, in which there is a net gain or loss of genetic material, lead to the development of many human genetic disorders. ${ }^{42}$

In addition, a significant increase in the frequency of fragilities (fra), increase in length of heterochromatic segments on the long arms of chromosome $1(1 \mathrm{qh}+)$ and chromosome $16(16 \mathrm{qh}+)$ and chromosomal and chromatidic breakages (chrb/chtb) were also observed in the exposed compared with the unexposed group. Fragilities are unstable regions of the genome $^{43}$ that can lead to the formation of complex CAs, including sister chromatid exchanges, ${ }^{44}$ duplications, ${ }^{45}$ intrachromosomal gene amplification, ${ }^{46}$ deletions and translocations, ${ }^{47,48}$ among others. All the above CAs have been associated with the development of cancer. ${ }^{49,50}$ In fact, many tumor suppressor genes and oncogenes have been located within fragile sites. ${ }^{51}$ Among the fragilities identified in this study, fra(9)(q12) was the most frequently observed in the exposed individuals. Interestingly, this fragility was observed by us in high frequency, in a Colombian population with breast cancer ${ }^{52}$ and also in individuals occupationally exposed to paint removers. ${ }^{53}$ Therefore, we suggest that fra (9)(q12) could be considered as a cytogenetic biomarker of chromosomal damage associated with pesticide exposure.

With respect to the increase in the length of heterochromatin segments, Atkin, et $\mathrm{al}^{54}$ suggested susceptibility to malignancy associated mainly with heteromorphisms in chromosome 1. In addition, several groups have reported the presence of heterochromatin variation on chromosomes 1,9 and 16, in patients with various malignant tumors including ovarian, breast and hematological disorders, among others. $^{55-57}$ To highlight that, scoring of chromosomal breakages has been used to monitor populations with increased cancer risk due to carcinogen exposure. ${ }^{58-60}$ Moreover, chromosomal breakages generally produce nonrecurrent chromosomal aberrations (NCCAs), ${ }^{61}$ which are indicative of CIN.

In addition, CIN was also evaluated by using FISH. This method allowed us to identify, in each exposed and exposed individual, the variations in the modal number of 


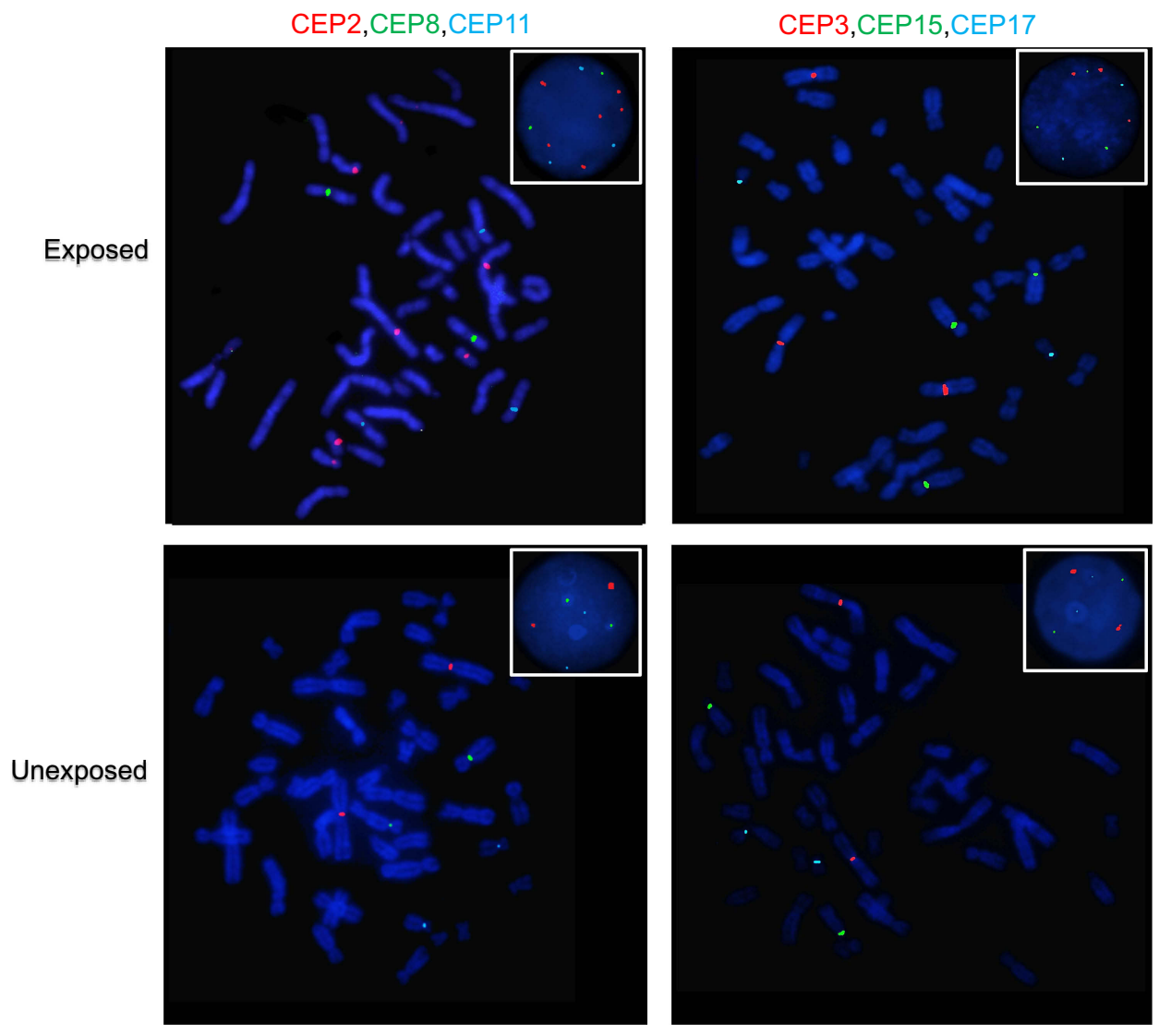

Figure 5 Representative FISH images of an exposed and an unexposed individual. Metaphase spreads are shown and boxes indicate representative interphase nuclei for each case. In the exposed individual, more than two signals are observed for chromosomes 2, 3, 8, II, I5 and I7, which is indicative of chromosomal instability. While in the unexposed individual, for each of the chromosomes indicated above, a normal number of signals (two signals) are observed. Three-color FISH was performed on nuclei spreads for chromosomes 2, 8 and II and, chromosomes 3, 15 and 17 using centromeric probes (CEP) labeled with different spectrum colors: spectrum orange for CEP2 and CEP3; spectrum green for CEP8 and CEPI7; and spectrum aqua for CEPII and CEPI5.

chromosomes $2,3,8,11,15$ and 17 . Our results show that individuals exposed to pesticides have a high frequency of aneuploidy (high CIN) compared to low aneuploidy (low CIN) observed in unexposed individuals. Some studies have shown that a wide range of chemicals, classified as aneugens, are capable of inducing aneuploidy both in vitro and in vivo. ${ }^{62}$ Thus, it has been reported that exposure to low concentrations of potentially aneugenic chemicals, such as pesticides, can induce carcinogenesis. ${ }^{63}$ The mechanisms through which pesticides induce aneuploidy are not well known. Aneugenic chemicals may lead to chromosome loss and non-disjunction by interacting with a variety of cell components and activities, such as synthesis and functioning of the spindle fibres, ${ }^{64}$ activity of the centrosome and modification of centromeres. ${ }^{65}$ Additionally, it has been reported that chemically induced aneuploidy may be extremely relevant for environmental carcinogenesis. ${ }^{66}$ To our knowledge, this is the first study to assess numerical CIN using six centromeric FISH probes in individuals occupationally exposed to pesticides.
Together, our results show that exposure to pesticides is associated with a significant increase in CIN. CIN is characterized by cell-to-cell variability in the number or structure of chromosomes in a given cell population, ${ }^{67}$ and by the presence of clonal (CCAs) and non-clonal alterations (NCCAs). Considering that CCAs are recurrent chromosomal alterations (alterations found at least twice in a population of 20-40 mitosis), and NCCAs are present in a population of cells in a non-recurrent manner, ${ }^{68}$ our results not only suggest that pesticides induce $\mathrm{CIN}$ but also high levels of heterogeneity. In fact, it has been reported that NCCAs reflect a more unstable system and are a stronger indicator of CIN. ${ }^{67,69}$ In addition, CCAs and NCCAs can lead to expansion of chromosomal alterations and, therefore, to a general increase in heterogeneity. Both CIN and heterogeneity reflect the instability of the system and may predispose cells to acquire additional CAs and, therefore, to a higher risk of malignant transformation. ${ }^{70,71}$ In fact, a linear trend between CAs in PBLs and subsequent cancer risk has been shown by several prospective cancer studies. $^{29,72-75}$ 
Most of the farmers in our study were exposed to complex mixtures of pesticides. Considering that pesticides come in many different formulations due to variations in the active ingredient's solubility, ability to control the pest, and ease of handling and transport, it is very difficult to determine whether the chromosomal damage observed in exposed individuals is due to a specific pesticide. Furthermore, variable combinations of products are often used. ${ }^{17}$ In addition, pesticides generally have different biological modes of action. For example, it has been reported that mancozeb, one of the pesticides used by farmers in this study, interferes with the synthesis, metabolism, transportation, and elimination of hormones, which results in decreased natural hormone concentrations. ${ }^{76}$ Paraquat, besides being the second most widely used herbicide, ${ }^{77}$ also has been associated with an increased risk of Parkinson's disease. ${ }^{78}$ Another of the pesticides used by the exposed group is Carbosulfan. This insecticide is a potent genotoxic agent and a potent germ cell mutagen. ${ }^{79}$ In fact, it has been reported that the exposure of mice to this insecticide increases the formation of bone marrow micronuclei, chromosomal abnormalities and sperm alterations. ${ }^{77}$

The high frequency of CVs and CAs observed in the exposed group might result from pesticide-induced oxidative stress. Oxidative stress is known to cause DNA damage, which in turn may cause health disorders including Parkinson's disease, ${ }^{78}$ endocrine disruption, ${ }^{80}$ respiratory and reproductive disorders, ${ }^{81}$ Hodgkin's disease, nonHodgkin lymphoma, ${ }^{82}$ leukemia, Burkitt lymphoma, ovarian cancer, neuroblastoma, soft tissue sarcoma, ${ }^{83}$ and cancers of the lung, rectum, stomach, bladder, colon and breast. ${ }^{84,85}$

Considering that the mutagenic risk of various cigarette components is considered a confounding factor that can influence the frequency of CVs and CAs, we analyze whether smoking and alcohol consumption in both the exposed and unexposed individuals affect the frequency of chromosomal damage. Our results show that smoking does not increase the frequency of chromosomal damage in the exposed 5 (E5), the only exposed individual who indicated being a smoker. This result may be due to the fact that the average daily cigarette intake of E5 is 3, so according to the criteria considered by Calderón-Ezquerro et al (2007), ${ }^{86}$ the E5 can be classified as a light smoker $(<19 \pm 3.88$ cigarettes/day), so this amount is insufficient to cause an effect on PBLs. Additional studies found no effect of smoking habit on workers exposed to pesticides and whose intake was between 22 and 25 cigarettes/day. ${ }^{87}$ With regard to alcohol consumption, our results showed no associations between alcohol consumption and increased in the frequency of CVs and CAs. Similar findings have been previously reported, which indicate that the increase in the frequency of chromosomal damage is not related to alcohol consumption in people exposed to pesticides. ${ }^{88}$

\section{Conclusions}

The results obtained from the analysis of a large number of metaphases for using GTG-Banding and FISH allowed us to identify previously unreported chromosome variants (CVs) and CAs in farmers exposed to pesticides. The results of our study, although conducted on a small number of individuals, suggest a deleterious effect of pesticides on chromosomes as well as the association between them with a significant increase in CIN. Considering that CIN can predispose cells to additional chromosomal alterations and, therefore, to an increased risk of developing diseases, the establishment of educational programs on safety precautions when handling pesticides, such as wearing boots and masks, gloves, changing clothes and maintaining proper hygiene, among others, is urgent and necessary. Our study provides relevant information for further evaluation with a greater number of individuals.

\section{Acknowledgments}

We thank Dr. Nelson Rangel for excellent assistance with statistical analysis and for critical reading of the manuscript. We thank Jeremy Allen, PhD, from Edanz Group for editing a draft of this manuscript.

\section{Disclosure}

The authors report no conflicts of interest in this work.

\section{References}

1. Bolognesi C. Genotoxicity of pesticides: a review of human biomonitoring studies. Mutat Res. 2003;543(3):251-272. doi:10.1016/S13835742(03)00015-2

2. Kaur K, Kaur R. Occupational pesticide exposure, impaired DNA repair, and diseases. Indian J Occup Environ Med. 2018;22 (2):74-81. doi:10.4103/ijoem.IJOEM_45_18

3. Mostafalou S, Abdollahi M. Pesticides: an update of human exposure and toxicity. Arch Toxicol. 2017;91(2):549-599.

4. Hernandez AF, Parron T, Tsatsakis AM, Requena M, Alarcon R, LopezGuarnido O. Toxic effects of pesticide mixtures at a molecular level: their relevance to human health. Toxicology. 2013;307:136-145. doi:10.1016/j.tox.2012.06.009

5. Koureas M, Tsezou A, Tsakalof A, Orfanidou T, Hadjichristodoulou C. Increased levels of oxidative DNA damage in pesticide sprayers in thessaly region (Greece). Implications of pesticide exposure. Sci Total Environ. 2014;496:358-364. doi:10.1016/j.scitotenv.2014.07.062

6. Ji BT, Silverman DT, Stewart PA, et al. Occupational exposure to pesticides and pancreatic cancer. Am J Ind Med. 2001;39(1):92-99. doi:10.1002/1097-0274(200101)39:1<92::AID-AJIM9>3.0.CO;2-P 
7. Dulout FN, Pastori MC, Olivero OA, et al. Sister-chromatid exchanges and chromosomal aberrations in a population exposed to pesticides. Mutat Res. 1985;143(4):237-244. doi:10.1016/01657992(85)90087-9

8. De Ferrari M, Artuso M, Bonassi S, et al. Cytogenetic biomonitoring of an Italian population exposed to pesticides: chromosome aberration and sister-chromatid exchange analysis in peripheral blood lymphocytes. Mutat Res. 1991;260(1):105-113. doi:10.1016/01651218(91)90086-2

9. Rupa DS, Reddy PP, Sreemannarayana K, Reddi OS. Frequency of sister chromatid exchange in peripheral lymphocytes of male pesticide applicators. Environ Mol Mutagen. 1991;18(2):136-138. doi:10.1002/ em. 2850180209

10. Balaji M, Sasikala K. Cytogenetic effect of malathion in in vitro culture of human peripheral blood. Mutat Res. 1993;301(1):13-17. doi:10.1016/0165-7992(93)90050-6

11. Carbonell E, Xamena N, Creus A, Marcos R. Cytogenetic biomonitoring in a Spanish group of agricultural workers exposed to pesticides. Mutagenesis. 1993;8(6):511-517. doi:10.1093/mutage/8.6.511

12. Brega SM, Vassilieff I, Almeida A, et al. Clinical, cytogenetic and toxicological studies in rural workers exposed to pesticides in Botucatu, Sao Paulo, Brazil. Cad Saude Publica. 1998;14(Suppl 3):109-115. doi:10.1590/S0102-311X1998000700011

13. Carbonell E, Puig M, Xamena N, Creus A, Marcos R. Sister chromatid exchange in lymphocytes of agricultural workers exposed to pesticides. Mutagenesis. 1990;5(4):403-405. doi:10.1093/mutage/5.4.403

14. Gomez-Arroyo S, Noriega-Aldana N, Osorio A, Galicia F, Ling S, Villalobos-Pietrini R. Sister-chromatid exchange analysis in a rural population of Mexico exposed to pesticides. Mutat Res. 1992;281 (3):173-179. doi:10.1016/0165-7992(92)90005-3

15. Prabhavathy Das G, Pasha Shaik A, Jamil K. Cytotoxicity and genotoxicity induced by the pesticide profenofos on cultured human peripheral blood lymphocytes. Drug Chem Toxicol. 2006;29 (3):313-322. doi:10.1080/01480540600653093

16. Gomez-Arroyo S, Diaz-Sanchez Y, Meneses-Perez MA, VillalobosPietrini R, De Leon-rodriguez J. Cytogenetic biomonitoring in a Mexican floriculture worker group exposed to pesticides. Mutat Res. 2000;466(1):117-124. doi:10.1016/S1383-5718(99)00231-4

17. Bull S, Fletcher K, Boobis AR, Battershill JM. Evidence for genotoxicity of pesticides in pesticide applicators: a review. Mutagenesis. 2006;21(2):93-103. doi:10.1093/mutage/gel011

18. Remor AP, Totti CC, Moreira DA, Dutra GP, Heuser VD, Boeira JM. Occupational exposure of farm workers to pesticides: biochemical parameters and evaluation of genotoxicity. Environ Int. 2009;35 (2):273-278. doi:10.1016/j.envint.2008.06.011

19. Silins I, Hogberg J. Combined toxic exposures and human health: biomarkers of exposure and effect. Int J Environ Res Public Health. 2011;8(3):629-647. doi:10.3390/ijerph8030629

20. Gentile N, Manas F, Bosch B, Peralta L, Gorla N, Aiassa D. Micronucleus assay as a biomarker of genotoxicity in the occupational exposure to agrochemicals in rural workers. Bull Environ Contam Toxicol. 2012;88(6):816-822. doi:10.1007/s00128-012-0589-8

21. Bonassi S, Hagmar L, Stromberg U, et al. Chromosomal aberrations in lymphocytes predict human cancer independently of exposure to carcinogens. European Study Group on Cytogenetic Biomarkers and Health. Cancer Res. 2000;60(6):1619-1625.

22. ISCN 2016. An International System for Human Cytogenomic Nomenclature (2016). Vol. 149. Basel (Switzerland): Karger; 2016.

23. Takami S, Kawasome C, Kinoshita M, Koyama H, Noguchi S. Chromosomal instability detected by fluorescence in situ hybridization in Japanese breast cancer patients. Clin Chim Acta. 2001;308 (1-2):127-131. doi:10.1016/S0009-8981(01)00473-9

24. Farabegoli F, Santini D, Ceccarelli C, Taffurelli M, Marrano D, Baldini N. Clone heterogeneity in diploid and aneuploid breast carcinomas as detected by FISH. Cytometry. 2001;46(1):50-56. doi:10.1002/(ISSN)1097-0320
25. Lengauer C, Kinzler KW, Vogelstein B. Genetic instability in colorectal cancers. Nature. 1997;386(6625):623-627. doi:10.1038/386623a0

26. Munro AF, Twelves C, Thomas JS, Cameron DA, Bartlett JM. Chromosome instability and benefit from adjuvant anthracyclines in breast cancer. $B r \quad J$ Cancer. 2012;107(1):71-74. doi:10.1038/ bjc. 2012.232

27. Kawauchi S, Furuya T, Ikemoto K, et al. DNA copy number aberrations associated with aneuploidy and chromosomal instability in breast cancers. Oncol Rep. 2010;24(4):875-883. doi:10.3892/or.2010.875

28. Talamo A, Chalandon Y, Marazzi A, Jotterand M. Clonal heterogeneity and chromosomal instability at disease presentation in high hyperdiploid acute lymphoblastic leukemia. Cancer Genet Cytogenet. 2010;203 (2):209-214. doi:10.1016/j.cancergencyto.2010.09.005

29. Hagmar L, Bonassi S, Stromberg U, et al. Chromosomal aberrations in lymphocytes predict human cancer: a report from the European Study Group on Cytogenetic Biomarkers and Health (ESCH). Cancer Res. 1998;58(18):4117-4121.

30. Baris D, Silverman DT, Brown LM, et al. Occupation, pesticide exposure and risk of multiple myeloma. Scand $J$ Work Environ Health. 2004;30(3):215-222. doi:10.5271/sjweh.782

31. Lumley M, Barker H, Murray JA. Benzene in petrol. Lancet. 1990;336(8726):1318-1319. doi:10.1016/0140-6736(90)93002-7

32. Invernizzi P, Miozzo M, Battezzati PM, et al. Frequency of monosomy X in women with primary biliary cirrhosis. Lancet. 2004;363 (9408):533-535. doi:10.1016/S0140-6736(04)15541-4

33. Invernizzi P, Pasini S, Selmi C, Gershwin ME, Podda M. Female predominance and $\mathrm{X}$ chromosome defects in autoimmune diseases. J Autoimmun. 2009;33(1):12-16. doi:10.1016/j.jaut.2009.03.005

34. Invernizzi P, Miozzo M, Selmi C, et al. X chromosome monosomy: a common mechanism for autoimmune diseases. J Immunol. 2005;175(1):575-578. doi:10.4049/jimmunol.175.1.575

35. Bianchi I, Lleo A, Bernuzzi F, Caliari L, Smyk DS, Invernizzi P. The $\mathrm{X}$-factor in primary biliary cirrhosis: monosomy $\mathrm{X}$ and xenobiotics. Auto Immun Highlights. 2012;3(3):127-132. doi:10.1007/s13317-0120043-2

36. Gershwin ME, Mackay IR. The causes of primary biliary cirrhosis: convenient and inconvenient truths. Hepatology. 2008;47(2):737-745. doi:10.1002/hep. 22042

37. Selmi C, Gershwin ME. The role of environmental factors in primary biliary cirrhosis. Trends Immunol. 2009;30(8):415-420. doi:10.1016/ j.it.2009.05.006

38. Smyk D, Rigopoulou EI, Baum H, Burroughs AK, Vergani D, Bogdanos DP. Autoimmunity and environment: am I at risk? Clin Rev Allergy Immunol. 2012;42(2):199-212. doi:10.1007/s12016-011$8259-\mathrm{x}$

39. Estalilla O, Rintels P, Mark HF. Trisomy 10 in leukemia. Cancer Genet Cytogenet. 1998;101(1):68-71. doi:10.1016/S0165-4608(97)00056-3

40. Ohyashiki K, Kodama A, Nakamura H, et al. Trisomy 10 in acute myeloid leukemia. Cancer Genet Cytogenet. 1996;89(2):114-117. doi:10.1016/0165-4608(95)00263-4

41. Williams BR, Amon A. Aneuploidy: cancer's fatal flaw? Cancer Res. 2009;69(13):5289-5291. doi:10.1158/0008-5472.CAN-09-0944

42. Theisen A, Shaffer LG. Disorders caused by chromosome abnormalities. Appl Clin Genet. 2010;3:159-174. doi:10.2147/TACG. S 8884

43. Glover TW. Instability at chromosomal fragile sites. Recent Results Cancer Res. 1998;154:185-199. doi:10.1007/978-3-642-46870-4_11

44. Glover TW, Stein CK. Induction of sister chromatid exchanges at common fragile sites. Am J Hum Genet. 1987;41(5):882-890.

45. Hellman A, Zlotorynski E, Scherer SW, et al. A role for common fragile site induction in amplification of human oncogenes. Cancer Cell. 2002;1(1):89-97. doi:10.1016/S1535-6108(02)00017-X

46. Coquelle A, Pipiras E, Toledo F, Buttin G, Debatisse M. Expression of fragile sites triggers intrachromosomal mammalian gene amplification and sets boundaries to early amplicons. Cell. 1997;89(2):215-225. doi:10.1016/S0092-8674(00)80201-9 
47. Durkin SG, Glover TW. Chromosome fragile sites. Annu Rev Genet. 2007;41:169-192. doi:10.1146/annurev.genet.41.042007.165900

48. Re A, Cora D, Puliti AM, Caselle M, Sbrana I. Correlated fragile site expression allows the identification of candidate fragile genes involved in immunity and associated with carcinogenesis. $B M C$ Bioinformatics. 2006;7:413. doi:10.1186/1471-2105-7-413

49. Vincent-Salomon A, Benhamo V, Gravier E, et al. Genomic instability: a stronger prognostic marker than proliferation for early stage luminal breast carcinomas. PLoS One. 2013;8(10):e76496. doi:10.1371/journal.pone. 0076496

50. Debacker K, Kooy RF. Fragile sites and human disease. Hum Mol Genet. 2007;16(2):R150-R158. doi:10.1093/hmg/ddm136

51. Popescu NC. Genetic alterations in cancer as a result of breakage at fragile sites. Cancer Lett. 2003;192(1):1-17. doi:10.1016/S03043835(02)00596-7

52. Rondón M, Caicedo J, Robledo J. Establishment of chromosomic abnormalities and amplified DNA sequences in breast cancer. Revista Ciencias de la Salud. 2006;4(2):15.

53. Villalba-Campos M, Chuaire-Noack L, Sanchez-Corredor MC, Rondon-Lagos M. High chromosomal instability in workers occupationally exposed to solvents and paint removers. Mol Cytogenet. 2016;9:46. doi:10.1186/s13039-016-0256-6

54. Atkin NB. Chromosome 1 heteromorphism in patients with malignant disease: a constitutional marker for a high-risk group? $\mathrm{Br}$ Med $J$. 1977;1(6057):358. doi:10.1136/bmj.1.6057.358

55. Shabtai F, Halbrecht I. Risk of malignancy and chromosomal polymorphism: a possible mechanism of association. Clin Genet. 1979;15 (1):73-77. doi:10.1111/j.1399-0004.1979.tb02029.x

56. Aguilar L, Lisker R, Ruz L, Mutchinick O. Constitutive heterochromatin polymorphisms in patients with malignant diseases. Cancer. 1981;47(10):2437-2439. doi:10.1002/(ISSN)1097-0142

57. Petkovic I. Constitutive heterochromatin of chromosomes No. 1, 9, and 16 in 90 patients with malignant disease and 91 controls. Cancer Genet Cytogenet. 1983;10(2):151-158. doi:10.1016/0165-4608(83)90119-X

58. Wu X, Zheng YL, Hsu TC. Mutagen-induced chromatid breakage as a marker of cancer risk. Methods Mol Biol. 2005;291:59-67. doi:10.1385/1-59259-840-4:059

59. Bonassi S, Abbondandolo A, Camurri L, et al. Are chromosome aberrations in circulating lymphocytes predictive of future cancer onset in humans? Preliminary results of an Italian cohort study. Cancer Genet Cytogenet. 1995;79(2):133-135. doi:10.1016/01654608(94)00131-T

60. Bonassi S, Znaor A, Norppa H, Hagmar L. Chromosomal aberrations and risk of cancer in humans: an epidemiologic perspective. Cytogenet Genome Res. 2004;104(1-4):376-382. doi:10.1159/000077519

61. Heng HH, Liu G, Bremer S, Ye KJ, Stevens J, Ye CJ. Clonal and non-clonal chromosome aberrations and genome variation and aberration. Genome. 2006;49(3):195-204. doi:10.1139/g06-023

62. Parry JM, Parry EM, Bourner R, et al. The detection and evaluation of aneugenic chemicals. Mutat Res. 1996;353(1-2):11-46. doi:10.1016/0027-5107(95)00242-1

63. Bolt HM, Foth H, Hengstler JG, Degen GH. Carcinogenicity categorization of chemicals-new aspects to be considered in a European perspective. Toxicol Lett. 2004;151(1):29-41. doi:10.1016/j.toxlet.2004.04.004

64. Zijno A, Marcon F, Leopardi P, Crebelli R. Analysis of chromosome segregation in cytokinesis-blocked human lymphocytes: non-disjunction is the prevalent damage resulting from low dose exposure to spindle poisons. Mutagenesis. 1996;11(4):335-340. doi:10.1093/mutage/ 11.4.335

65. Renzi L, Pacchierotti F, Russo A. The centromere as a target for the induction of chromosome damage in resting and proliferating mammalian cells: assessment of mitomycin C-induced genetic damage at kinetochores and centromeres by a micronucleus test in mouse splenocytes. Mutagenesis. 1996;11(2):133-138. doi:10.1093/mutage/11.2.133
66. Mattiuzzo M, Fiore M, Ricordy R, Degrassi F. Aneuploidy-inducing capacity of two widely used pesticides. Carcinogenesis. 2006;27 (12):2511-2518. doi:10.1093/carcin/bgl102

67. Heng HH, Bremer SW, Stevens JB, et al. Chromosomal instability (CIN): what it is and why it is crucial to cancer evolution. Cancer Metastasis Rev. 2013;32(3-4):325-340. doi:10.1007/s10555-0139427-7

68. Giam M, Rancati G. Aneuploidy and chromosomal instability in cancer: a jackpot to chaos. Cell Div. 2015;10:3. doi:10.1186/ s13008-015-0009-7

69. Rangel N, Forero-Castro M, Rondon-Lagos M. New insights in the cytogenetic practice: karyotypic chaos, non-clonal chromosomal alterations and chromosomal instability in human cancer and therapy response. Genes (Basel). 2017;8(6). doi:10.3390/genes8060155

70. Pikor L, Thu K, Vucic E, Lam W. The detection and implication of genome instability in cancer. Cancer Metastasis Rev. 2013;32(3-4):341-352. doi:10.1007/s10555-013-9429-5

71. Zhang L, Lan Q, Guo W, et al. Chromosome-wide aneuploidy study (CWAS) in workers exposed to an established leukemogen, benzene. Carcinogenesis. 2011;32(4):605-612. doi:10.1093/carcin/bgq286

72. Lan Q, Zhang L, Li G, et al. Hematotoxicity in workers exposed to low levels of benzene. Science. 2004;306(5702):1774-1776. doi:10.1126/science. 1102443

73. Jang JE, Min YH, Yoon J, et al. Single monosomy as a relatively better survival factor in acute myeloid leukemia patients with monosomal karyotype. Blood Cancer J. 2015;5:e358. doi:10.1038/ bcj. 2015.84

74. Farkas G, Szekely G, Vass N, Kiss K, Gundy S. Rate of spontaneous numerical chromosome aberrations in Hungarian healthy population. Magy Onkol. 2015;59(3):198-204.

75. Vodenkova S, Polivkova Z, Musak L, et al. Structural chromosomal aberrations as potential risk markers in incident cancer patients. Mutagenesis. 2015;30(4):557-563. doi:10.1093/mutage/gev018

76. Akhtar N, Kayani SA, Ahmad MM, Shahab M. Insecticide-induced changes in secretory activity of the thyroid gland in rats. $J$ Appl Toxicol. 1996;16(5):397-400. doi:10.1002/(ISSN)1099-1263

77. Sabarwal A, Kumar K, Singh RP. Hazardous effects of chemical pesticides on human health-Cancer and other associated disorders. Environ Toxicol Pharmacol. 2018;63:103-114. doi:10.1016/j. etap.2018.08.018

78. Brouwer M, Huss A, van der Mark M, et al. Environmental exposure to pesticides and the risk of Parkinson's disease in the Netherlands. Environ Int. 2017;107:100-110. doi:10.1016/j.envint.2017.07.001

79. Giri S, Giri A, Sharma GD, Prasad SB. Mutagenic effects of carbosulfan, a carbamate pesticide. Mutat Res. 2002;519(1-2):75-82. doi:10.1016/S1383-5718(02)00114-6

80. Mazur CS, Marchitti SA, Zastre J. P-glycoprotein inhibition by the agricultural pesticide propiconazole and its hydroxylated metabolites: implications for pesticide-drug interactions. Toxicol Lett. 2015;232 (1):37-45. doi:10.1016/j.toxlet.2014.09.020

81. Kirkhorn SR, Schenker MB. Current health effects of agricultural work: respiratory disease, cancer, reproductive effects, musculoskeletal injuries, and pesticide-related illnesses. J Agric Saf Health. 2002;8(2):199-214. doi:10.13031/2013.8432

82. Luo D, Zhou T, Tao Y, Feng Y, Shen X, Mei S. Exposure to organochlorine pesticides and non-Hodgkin lymphoma: a meta-analysis of observational studies. Sci Rep. 2016;6:25768. doi:10.1038/srep25768

83. Polanco Rodriguez AG, Riba Lopez MI, DelValls Casillas TA, Araujo Leon JA, Mahjoub O, Prusty AK. Monitoring of organochlorine pesticides in blood of women with uterine cervix cancer. Environ Pollut. 2017;220(Pt B):853-862. doi:10.1016/j.envpol.2016.10.068

84. Bonner MR, Freeman LE, Hoppin JA, et al. Occupational exposure to pesticides and the incidence of lung cancer in the agricultural health study. Environ Health Perspect. 2017;125(4):544-551. doi:10.1289/EHP456 
85. Xu X, Dailey AB, Talbott EO, Ilacqua VA, Kearney G, Asal NR. Associations of serum concentrations of organochlorine pesticides with breast cancer and prostate cancer in U.S. adults. Environ Health Perspect. 2010;118(1):60-66. doi:10.1289/ehp.0900919

86. Calderon-Ezquerro C, Sanchez-Reyes A, Sansores RH, et al. Cell proliferation kinetics and genotoxicity in lymphocytes of smokers living in Mexico City. Hum Exp Toxicol. 2007;26(9):715-722. doi:10.1177/0960327107083451
87. Ergene S, Celik A, Cavas T, Kaya F. Genotoxic biomonitoring study of population residing in pesticide contaminated regions in Goksu Delta: micronucleus, chromosomal aberrations and sister chromatid exchanges. Environ Int. 2007;33(7):877-885. doi:10.1016/j.envint. 2007.04.003

88. Sailaja N, Chandrasekhar M, Rekhadevi PV, et al. Genotoxic evaluation of workers employed in pesticide production. Mutat Res. 2006;609(1):74-80. doi:10.1016/j.mrgentox.2006.06.022

\section{Publish your work in this journal}

Risk Management and Healthcare Policy is an international, peerreviewed, open access journal focusing on all aspects of public health, policy, and preventative measures to promote good health and improve morbidity and mortality in the population. The journal welcomes submitted papers covering original research, basic science, clinical \& epidemiological studies, reviews and evaluations, guidelines, expert opinion and commentary, case reports and extended reports. The manuscript management system is completely online and includes a very quick and fair peer-review system, which is all easy to use. Visit http://www.dovepress.com/testimonials.php to read real quotes from published authors. 